\title{
For-chat: uma comunidade virtual construindo sentido, autoria e conceitos em um ambiente cooperativamente interativo
}

\author{
Querte Teresinha Conzi Mehlecke \\ $\mathrm{Dr}^{\mathrm{a}}$ Margarete $\mathrm{Axt}^{2}$ \\ Dr $^{\mathrm{a}}$ Liane Margarida Rockenbach Tarouco ${ }^{3}$
}

Resumo: A comunicação mediada por computador é um elemento fundamental no processo de ensino e aprendizagem em ambientes de educação a distância. Neste sentido, o for-chat (ferramenta de comunicação síncrona e assíncrona) foi o meio pelo qual procurou-se, através da teoria de Bakhtin, aplicar a prática, estudando o discurso, autoria e conceitos construídos pelos estudantes no decorrer das interações nesse ambiente. Destaca-se alguns diálogos que ilustram as interações e autorias coletivas, cujos resultados propiciarão uma reflexão dos efeitos do for-chat no processo de ensino e aprendizagem nos ambientes virtuais.

Palavras-chave: For-chat, sentido, autoria, discurso, ambiente virtual de aprendizagem

\begin{abstract}
The communication mediated by computer is a basic element in the teaching and learning process in the distance education environments. In this direction, the forchat (tool of synchronous and asynchronous communication) was a way, through the theory of Bakhtin, to apply to the practical situations, studying the speech, authorship and concepts constructed by the students while the interactions happened in this environment. It is distinguished some dialogues that illustrate the interactions and collective authorship, whose results will propitiate a reflection of the effects of the forchat in the process of teaching and learning in virtual environments.
\end{abstract}

Key words: For-chat, meaning, authorship, speech, learning virtual environment

\footnotetext{
${ }^{1}$ Doutoranda do Programa de Pós-Graduação em Informática da Educação -UFRGS/PGIE.

${ }^{2}$ Professora do Depto. De Estudos Especializados da Faculdade de Educação/UFRGS. Professora do Programa de Pós-Graduação em Educação da UFRGS e do Programa de Pós-Graduação em Informática na Educação da UFRGS. Coordenadora do Laboratório de Estudos em Linguagem, Interação e Cognição (LELIC/PPGEdu/UFRGS).

${ }^{3}$ Professora Dra do Programa de Pós-Graduação em Ciência da Computação/ UFRGS e do Programa de Pós-Graduação em Informática na Educação da UFRGS. Diretora do Centro Interdisciplinar de Novas Tecnologias na Educação.
} 


\section{Introdução}

Este artigo apresenta um estudo sobre o sentido, autoria e discurso num ambiente virtual de aprendizagem - for-chat, utilizado no Seminário Avançado: Sentido e Autoria Em Ambientes Virtuais De Aprendizagem: Condições De Possibilidade, In(Ter)Venção E Avaliação, realizado no período de maio/outubro de 2002, ministrado pela prof ${ }^{a}$ Dr $^{a}$ Margarete Axt.

O estudo focaliza o for-chat, ferramenta de comunicação síncrona e assíncrona desenvolvida no Laboratório de Estudos em Linguagem Interação e Cognição Faculdade de Educação - UFRGS, sob o aspecto tecnológico, cultural e pedagógico, procurando fornecer ao leitor uma experiência de construção de conceitos, a partir das autorias e discursos no for-chat, ferramenta utilizada nas interações síncronas e assíncronas no Seminário Avançado.

Quanto ao aspecto tecnológico, o for-chat é apresentado em suas características funcional para $\mathrm{EaD}$. No que concerne aos aspectos culturais há uma busca de aproximação entre as características de escrita, autoria e sentido do discurso onde os participantes discutem as teorias sugeridas e outras adquiridas no decorrer de sua formação. No aspecto pedagógico, é focalizado no sentido das autorias e dos discursos numa comunidade virtual interativa, tendo como ponto principal deste estudo, os discursos apresentados no decorrer do seminário.

As novas propostas de como aprender, construir conhecimento e conceitos através do discurso, refletindo sobre ela, analisando os mais diversos aspectos e verificando as mudanças que podem desestruturar os modelos tradicionais se apresentam no for-chat o qual os textos ficam registrados de forma que podemos resgatar as mensagens assíncronamente, interagindo, relendo e contribuindo em qualquer parte do texto. É nesse sentido que Bakhtin(2000) fundamenta a presente análise ao dizer:

"Compreender é cortejar com outros textos e pensar num contexto novo (no meu contexto, no contexto contemporâneo, no contexto futuro). Contextos presumidos do futuro: a sensação de que estou dando um novo passo (de que me movimentei). Etapas da progressão dialógica da compreensão; o ponto de partida - o texto dado, para trás - os contextos passados, para frente - a presunção ( e o início) do contexto futuro. (p. 404)

É compreendendo o leitor, fazendo associações, interagindo, ligando a teoria com a prática que se encontra o sentido, aspecto que apresentamos na seção dois.

O conceito de autor expresso nos referenciais teóricos de Bakhtin, Axt, Fiorin e Barros, é apresentado na seção três, sustentado pelo recorte de alguns diálogos que caracterizam as teorias estudadas.

A seção quatro, apresenta o sentido dos discursos, utilizando os diálogos dos estudantes, fazendo uma ligação entre as teorias. 
A seção cinco traz um relato individual sobre a comunidade virtual que se formou no ambiente for-chat.

\section{Sentido: elo de ligação entre a teoria e a prática}

Com base nas interações forchateanas, a medida em que as contribuições surgiam, a associação da teoria com a prática apresentava sentido para o estudo. Foi a partir dessas associações que o elo entre a teoria e a prática passou a ter significado. A partir das experiências dos estudantes expressas nos textos, conforme Bakhtin(2000) sentido carece de uma pergunta, é a assimilação, e o que não responde a uma pergunta carece de sentido.

O encontro com o sentido se dá a partir das associações, pois ao estudar um teórico, ler um texto, só haverá sentido para o leitor se este estiver ligado às suas necessidades presentes passadas e futuras. "O sentido só existe para outro sentido, com o qual existe conjuntamente. O sentido não existe sozinho...”(Bakhtin, 2000, p. 386)

Foi por meio do for-chat que se possibilitou a produção de novos sentidos para a construção coletiva da aprendizagem, desenvolvendo autoria, criando discurso e modificando os sentidos, pois no momento em que se encontra o sentido para a leitura, passa-se a modificar o discurso, gerando autoria e dando um novo significado para a prática pedagógica.

A contribuição a seguir ilustra o que sente MA em relação ao sentido e a teoria.

MA-Todas as teorias discursivas não dão conta de explicar porque damos determinados sentidos para as coisas, ou porque alguma coisa é um ato falho dentro de uma seqüência (é dentro de uma interpretação também que algo se torna um lapso ou uma falha).

Observa-se que MA, buscou nas teorias a explicação de sentidos, assim, as teorias contribuem, mas só encontraremos sentido quando ela estiver relacionada com as ações e necessidades do meio em que vivemos.

\section{Autor \& Autoria: da teoria para a prática}

Para Bakhtin(2000), autor é aquele que cria, com palavras e teorias construídas no seu meio social e cultural, textos, poesias, música, pintura, arte. Autor é aquele que navega num mar de palavras e conhecimentos, criando discursos e autorias com sentido.

A produção do autor, é o resultado da leitura de vários autores, de conhecimentos anteriores, pois, segundo Bakhtin(2000), visto que: não se autora sozinho, a leitura de outros autores dá sustentação as autorias individuais e coletivas.

A autoria nos ambientes virtuais reflete a voz de muitos autores, pois um ambiente, onde as construções acontecem naturalmente entre os sujeitos participantes, em que a autoria de um se transforma na autoria de muitos compondo a autoria coletiva. Neste sentido Bakhtin(2000), nos diz que, não se é autor sozinho. 
O diálogo a seguir é um exemplo de autoria de dois participantes do for-chat que expressam em suas narrativas o que está acontecendo e o que estão sentindo no movimento das interações.

QM - 19/06 O que temos que fazer é nos posicionarmos claramente num clima de trocas, dizendo o que pensa, o que sabe, se concorda, discorda... desenvolver a autoria, tornar-se independente do professor, o que é uma tarefa difícil para nós que fomos educados dependentes do professor

JS - 19/06 Concordo totalmente com a QM na questão do assumir-se autor naquilo que se é desafiado a fazer, na tentativa de alcançar algum resultado produtivo (ainda que este pensamento represente o modelo mais positivista, do trabalho por resultados, mas que o "algo" feito dá um gostinho bom especialmente quando a gente se vê naquilo, isso é inegável! (Do meu ponto de vista, ora autora, ora observadora de minhas próprias autorias e muitas delas construídas em conjunto com outras cabecinhas com culturas bem distantes da minha. Falo das minhas co-autorias com colegas formadores de professores que utilizam as tecnologias digitais da Irlanda, Estados Unidos, Inglaterra, Uruguai e Argentina!

As interações surgem quando um participante levanta uma posição deixando em aberto possibilidades de intervenção de outros participantes. Com exemplo o citado, percebe-se uma fala onde houve a intervenção de um participante que concorda com o discurso anterior, transformando a autoria individual em coletiva. Diz-nos (Fernández, 1994), "A escrita é uma palavra, mas é uma palavra que se oferece para ser olhada; palavra que mostra nossa autoria no ato de ser produzida.” ( $p .14)$

Para Bakhtin(2000), o texto só vive em contato com o outro texto. Ao longo das interações virtuais, os textos foram crescendo, tornando-se vivos no ambiente com as intervenções e colaborações das leituras sugeridas no Seminário, outras leituras, de acordo com os interesses e necessidades de cada participante.

Inicialmente alguns estudantes apresentaram resistência em estudar a teoria apresentada no Seminário.

No texto de GL abaixo, observa-se tal resistência sobre o tema proposto na primeira parte do programa.

GL- 29/06 Agora é para a professora, tutora, orientadora, mediadora Margareth (rs). A questão da psicopedagogia pra mim tem sido muito complicada. Em $1^{\circ}$ lugar é a $1^{a}$ vez que me remeto a esse tipo de leitura. Em $2^{\circ}$ lugar vem a questão da ciência. A sociologia trabalha no contexto do coletivo. Crê que as ações humanas estão muito mais contidas na consciência coletiva do que na individual. ... Se formos procurar no marxismo, veremos que Marx nos fala que a ideologia é na verdade uma falsa consciência. Assim, me pergunto: esse desejo não é uma forma ideologia em transpor para o indivíduo a obrigação que deveria ser da classe dirigente? Não estaria esse desejo repleto de sentidos ideológicos?

Segue ele em sua argumentação dizendo:

GL - 6/7 Fiquei bloqueado, quando escuto a palavra psicopedagogia algo desencadeia em mim e aí não sai nada! rs e rs

Há coisas que nem a razão explica! rs Mas a verdade é que é a $1^{a}$ vez que tenho contato com a psicopedagogia, por isso ainda me sinto muito inseguro em dar qq opinião, fico 
ainda tentando fazer pontes dela com minhas leituras, mas não ouso ainda me colocar pq estou muito principiante nesse campo. estou deixando o texto dormir um pouco na minha cabeça e assim, quem sabe, num futuro bem próximo começar a "colocar pra fora" essas angústias intelectuais quem estão surgindo.

Em outra participação, MI associa-se a experiência de GL.

MI - 6/7 também passo por algo semelhante, fico com receio em fazer colocações absurdas, mas a fala da Margarete em aula hoje me deixou mais tranqüila e me motivou a me aventurar neste ambiente desconhecido

Nesse diálogo o estudante apresenta o papel fundamental do professor que encoraja os alunos a dizerem e escreverem o que pensam, o que entenderam e o que sabem. Em caso contrário, o ambiente seria um restritor para as interações e o professor ficaria sem saber o que de fato estava acontecendo.

Após os primeiros encontros, o colega GL se pronunciou na lista de discussão descrevendo o encontro com Alicia Fernández ( autora dos livros de psicopedagogia estudados num primeiro momento), o qual mudou o discurso e seguiu sua autoria, construindo um novo significado a partir do encontro. A oportunidade de discutir a temática vai além do conteúdo, pois o mesmo precisa ter sentido para o leitor, para este poder interagir, integrar, criticar, apresentar suas idéias comparando com os conhecimentos já adquiridos.

O texto a seguir apresenta parte do relato do GL do encontro com Alicia.

GL 08/07 ... Vou ter que dar a "mão à palmatória" e concordar com algumas coisas. Como diz Drummond: Eta vida besta, meu Deus!! rs e rs.

Vou "desvirginar meus dedos no teclado" para falar seriamente sobre psicopedagogia e, em particular, nossa temática sobre sentido e autoria.Lendo e assistindo Alicia me passa pela cabeça várias concepções sobre essas coisas da aprendizagem. Alicia tem uma idéia muito interessante sobre o papel do professor, que concordo em gênero, número e grau: "a arte do

professor é saber descobrir e mostrar a seus alunos o quanto eles pensam, inclusive sem perceberem isso" ( $O$ saber em jogo, pág. 93). Coisa boa isso, inclusive nos tira o peso de único detentores do saber, dividindo com nossos alunos a "obrigação" de pensar e nos fazendo ser "apenas" uma ponte que os leva ao "olimpo" da "arte de pensar". Criar condições para as pessoas aprenderem, compreenderem, criticarem $e$ etc. e etc., creio ser mais sublime do que lhes "dar" o aprendizado... Mas uma coisa, como um personagem do livro Saber... da Alicia, respondo: eu aprendi (rs)! De fato o caos é interessante e ele acaba apontando para algum lugar.

No discurso de GL acima, em um curto espaço de tempo, e o encontro com Alicia Fernández, convocou uma reflexão, mudando o discurso a partir da intervenção com um outro interlocutor ligado diretamente ao tema em estudo. Quando GL encontrou significado, arriscou-se a falar do assunto de outra perspectiva, até o momento "bloqueado" segundo ele.

A importância do encontro com o significado em nossa aprendizagem, buscando no relato de experiência de GL, mostrou que as primeiras leituras não seduziram o autor, o que o seduziu foi a fala com a própria autora e a motivação da professora Margarete. 
Contudo, a liberdade de expressão permitida no for-chat, foi o que incentivou a cada participante colocar os conhecimentos adquiridos, contribuir com leituras de outros autores e trocas de experiências. Assim, aos poucos, todos foram interagindo sem ficar estritamente ligados aos autores sugeridos, cada um fazendo suas contribuições relacionadas com o tema, ainda que com autores diferentes. Esse processo enriqueceu as produções e autorias individuais e coletivas, sendo que, dentre as contribuições de outros autores fazia-se a relação entre as diferentes teorias.

Nas palavras da professora Margarete(2002) “vamos correr o risco, ninguém tem a capacidade de deter a verdade". E foi correndo risco que construímos conceitos, autorias e modificamos nossos discursos a cada intervenção, a cada encontro virtual com leituras realizadas neste Seminário e em outras situações durante os encontros virtuais e presenciais.

A atuação da professora nos encontros presenciais e virtuais, foi fundamental, pois ela oportunizou novos os espaços de saber, liberdade de expressão, e em resposta deixamos no ambiente nossas obras, autorias, nossos sentidos. O grupo foi efetivo e afetivamente se constituindo com e pela professora através das interações, mediações, contribuições e acima de tudo, respeitando ela os conhecimentos adquiridos pelos participantes. Isso é fundamental pois o professor que ignora os conhecimentos vivos em seus alunos e quer transmitir conhecimentos seus sem deixar o grupo interagir com outros autores, certamente terá como resultado apenas o solicitado por ela sem novas autorias, sem novos sentidos. Nas ligações entre os autores, conceitos, culturas o ambiente e as contribuições enriqueceram-se ainda mais, e o resultado disso tudo podemos ver na satisfação em interagir no for-chat.

As diferenças entre os "forchateanos" foi o que puxou um ao outro nos diálogos, nas autorias, pois no momento em que cada participante citava um determinado autor, outros também resgatavam os seus autores, suas teorias para o interior virtual do for-chat, fazendo a relação entre uma e outra teoria, encadeando autorias e sentidos às suas práticas e vida de trabalho.

As autorias constuídas no for-chat tiveram um significado efetivo, diferente do que normalmente acontece em ambientes de aprendizagem presenciais Com isso fica um questionamento: - que ambiente presencial de aprendizagem, teríamos a oportunidade de ler, trocar idéias, autorar com tantas teorias, tantos autores e ficar tudo registrado?

\section{Discurso: um chamado ao diálogo}

O discurso é a linguagem em interação, e nessa seção apresentamos uma breve análise, fundamentada pelos comentários extraídos do for-chat.. Quando falamos dos discursos, estamos falando de autorias, relação de sentidos. Na análise de pequenos discursos, podemos refletir sobre a constituição de sentido no encontro com a voz do outro que propiciaram a mudança no discurso dos participantes. Em todo discurso são percebidos vozes, às vezes infinitamente distantes, anônimas, quase impessoais, quase imperceptíveis, assim como as vozes próximas que ecoam simultaneamente no momento da fala. (Bakhtin in Fiorim, 1994, p. 14) 
O diálogo a seguir é um exemplo de discurso que apresenta organização e interação da aprendizagem, onde um coopera com o outro dando significado a aprendizagem que se constitui Segundo Fiorin(1994) o discurso não se constrói sobre o mesmo, mas se elabora em vista do outro.

QM 08/07 Fazendo uma reflexão sobre as palavras do GL trago um complemento sobre o prazer da autoria. A cada pedacinho, cada capítulo do livro eu me identifico mais, pois acredito que não somente para mim para a maioria nos faz refletir e repensar em muitos momentos que já passamos. Eu vivi, tanto como professora e como aluna, grande parte dessas leituras. E fomos privados de sermos autores, e isso o tempo passa e vai ficando cada vez mais dificil aprender, mas quando percebemos que isso foi nos cortado e precisamos resgatar o sentido da autoria, nos dá uma grande satisfação. Indo um pouco além no livro a Mulher escondida na professora, pg 93 onde "O prazer da autoria - Escrever, cozinhar, escolher", Virgínia sente dificuldade em apresentar um trabalho escrito para um curso de sua especialidade. Apesar de apresentar vários trabalhos, esse estava muito difícil pois era diferente dos demais já apresentados. Diferente porque os outros eram sínteses ou comentários de pesquisas bibliográficas e esse era uma crítica sobre a opinião do autor.

Para ela opor-se significava agredir ou perder o afeto e as diferenças não significavam originalidade, mas sim deficiência. Quando Virginia estava conversando e trabalhando as dificuldades para questionar as idéias dos outros, comentou que não cozinhava sempre comprava comidas preparadas. Aí começaram a analisar a semelhança de suas atitudes antes dois processos diferentes, o de preparar e o de escolher a comida, o de preparar uma aula ou escrever um texto. Ela privava-se do prazer de sentir-se autora, tanto dos alimentos como dos conhecimentos a incorporar. Foi então que decidiu que queria comer e ir em busca dessa comida em particular. Aprender a cozinhar $e$ aprender a escrever criticamente, ser autora. Aprendeu a escrever e não registrar as palavras dos outros, com a maioria de nós.Poder escrever, sentir prazer por ser autor, escolher, decidir são ações que, em uma sociedade sexista, estão significadas como masculinas. Hoje não somos mais proibidas de escrever, mas estas proibições ficaram inscritas na forma de mandatos inconscientes que atuam antes mesmo de começarmos a escrever.

Como posso ser autora se eu dependo do meu professor para seguir adiante e encontrar um que deixe eu ser... estamos aqui para aprender, mas aprender e não ser copistas, precisamos aprender a pensar para nos tornarmos autores... Nessa caminhada é muito importante o papel do nosso orientador, pois ele nos dá a luz para seguirmos o caminho e nos deixa sermos autores.

GL 11/07 E vou junto com a QM nisso, mas acrescento que para ter autoria tem que ter pensamento. E o que é o pensamento? Clifford Geertz ("Saber Local") nos fala que o pensamento tem 2 sentidos: 1 - o ato ou o processo de pensar; cogitação e 2 - o produto do pensar; idéia; noção. Assim ele fala o seguinte: "para esclarecer o $1^{o}$, amplia-se o conceito de "processo" listando uma série de, como diríamos, fenômenos psicológicos internos: "atenção", "expectativa", "intenção" e até mesmo "esperança", dando a entender que a lista poderia incluir desde a memória e o sonho, até a imaginação e o cálculo, ou seja, tudo aquilo que, de alguma forma, possa ser definido como um "ato mental". Para esclarecer o $2^{\circ}$, dá-se o significado de "produto"; nesse caso, temos pomposa e indiscriminadamente, quase tudo aquilo que chamaríamos de cultura: a atividade ou produção intelectual de uma época ou grupo social específico. Pensamento é o que acontece dentro de nossas cabeças. E pensamento, principalmente quando vários deles são agrupados, é tbém o que SAI de nossas cabeças. (Saber, 1997, 220p.)" Geertz fala isso para chegar a uma boa conclusão: o pensamento não é unicamente constituído de "acontecimentos internos" (psicológicos)e, nem, somente de 
"acontecimentos externos" ( a cultura), mas também não é uma junção única disso. $\mathrm{Na}$ verdade, esse autor nos coloca que na nossa modernidade o "pensamento é uma multiplicidade de maneiras de pensar". Que ultrapassam, inclusive, os limites psi e culturais ("aí ele me bate, né?). Isso, me faz, continuar com o idéia de que a autoria TEM SENTIDO com sua época. Acho que PARA cada época um tipo de autoria e essa nossa época, como a Cristina já nos disse num dos e-mails da lista, é uma época multifocada, "multi-tudo" e "inter-tudo" (acrescento essas palavras), o pensamento toma forma como produto das formas culturais e psicológicas de hoje, por ele ser produto da atividade humana, portanto histórico, tem que estar esse pensamento como Geertz mesmo nos fala: numa variedade de formas. Com isso tudo, pegando carona com a QM sobre a pergunta da Prof. de autoria, começo a perceber que essa autoria vem a ser cada vez mais múltipla, cada vez mais multi-facetada,

"multi-tudo" (rs), já que ela é produto desse pensamento, talvez até o próprio pensamento (se ampliarmos o conceito de autoria). Será que fui claro?

Após o discurso, surge uma preocupação e um questionamento final, ficando a dúvida do locutor se conseguiu através das palavras transmitir a sua idéia. A interpretação do discurso deve ser respeitada pois é representada de forma individual, cada um com o seu nível de entendimento e compreensão.

O discurso dos autores como mediadores se revela nas interações. A cada novo discurso surge ligações dos elos entre a teoria estudada e as teorias conhecidas por cada participante. Segundo Palloff(2002), a abordagem colaborativa, faz sentido para os participantes quando há interesse e trocas de experiências a serem compartilhadas.

Os diferentes autores contribuem e instigam para que todos participem, cada um trazendo seu conhecimento e fazendo o elo de ligação "entre" uma teoria e outra, tornando o discurso potencialmente significativo para todos. De uma maneira ou outra, cada um convoca o outro para aquele momento e a participação com a bagagem teórica já incorporada, mesclando teorias e construindo novos conhecimentos a partir das interações.

Axt e Maraschin, nos dizem que a leitura do texto do outro instaura sentidos $e$ novos sentidos - na medida em que um texto é sempre um eco a um texto do outro-, a partir dos mesmos movimentos de retroação e provocação, de repetição e de abertura ao diferente e ás novas possibilidades. Assim, os discursos seguem novos caminhos, modificando-se ao encontrar os sentidos.

A interação entre os participantes, pequenos diálogos iam se transformando em grandes discursos, pois aos poucos novas contribuições surgiam, e aqueles que estavam observando, pouco a pouco arriscavam-se a dar uma paradinha no texto do outro e contribuir, interagindo de forma tímida mas com conhecimentos significativos, ou, em algumas vezes com questionamentos.

Os enunciados se presentificaram por meio de várias vozes tornando as participações do grupo mais efetivas a cada encontro. Assim os discursos se transformaram em intertextos. Para Fiorin e Barros(1994), pensar intertextualidade implica em romper com as amarras da seqüencialidade, funcionando em sintonia com conexões nada lineares. Deste modo os diferentes interlocutores, construíam e reconstruíam o discurso no ambiente for-chat em estudo. 
Segundo Bakhtin(2000) o sentido do discurso se dá a partir do dialogismo decorrente da interação verbal estabelecida entre o enunciador e o enunciatário, que aparece nas relações do eu-tu. Assim, a linguagem, as palavras, os textos é que dão vida aos discursos.

O discurso, seja qual for nunca é falado por uma única voz, mas sim por várias vozes, é autônomo, gerando vários textos. O discurso é a linguagem em interação, pois no decorrer das interações podemos ver claramente a linguagem expressa nos discursos. Falar em discurso é falar em condições de produção, suas formações, e para isso as relações, interações nos textos são fatores essenciais. Fiorim,(1994), observa que é necessário "no conjunto do enunciado, do discurso, de que forma a confluência das vozes significa muito mais uma interpretação do discurso alheio, ou a manipulação na direção da argumentação autoritária, ou mesmo a apropriação e subversão desse discurso.” (p. 25)

Em meio aos discursos, ficam questionamentos e provocações dos participantes, os quais esperam que novas contribuições surgissem. Observa-se no diálogo seguinte o que acontece quando o leitor encontra sentido no discurso do outro.

JA - Ao reler meus escritos, achei problemas técnicos vários, mas minha sensibilidade aflorou novamente (aquela por que me deixei possuir no ato da escrita deste Memorial 1). Lágrimas correram e senti-me novamente em ... curso ... marcha ... em busca do não dito... ainda! Mas muito obrigada, mesmo, pelo seu tempo em me percorrer, deixar-te tocar pelas minhas circunvoluções ununciáticas ... Coisas do Bakhtin!Tu és muito generosa, amiga!

ES- "Eu sempre cresço com meus problemas e desafios, com as coisas que não dão certo. Só então é que eu realmente aprendo." JA, tomei a liberdade de extrair este pedacinho de seu magnífico memorial para ter um motivo para comentar a respeito da importância de enfrentarmos os desafios com coragem e determinação. Penso que esta disciplina está realmente nos desafiando a buscar respostas a muitas das nossas dúvidas a respeito do que realmente faz sentido no nosso trabalho enquanto educadores. Quando vc falas das coisas que não dão certo como pontos importantes para a aprendizagem me lembra de Piaget e sua equilibração e desequilibração. Como é importante perdermos o equilíbrio de vez em quando para que possamos então construir novas aprendizagens

O encontro do sentido e significado no discurso do outro, "alimenta" e encoraja a participação. O encontro do "eu e o tu" é a fonte principal da comunicação, é o que dá sentido à aprendizagem, levando a construção dos conceitos e do conhecimento.

QM( Lévy,1993) em as Tecnologias da inteligência nos diz que "tomando os termos leitor e texto no sentido mais amplo possível, diremos que o objetivo de todo texto é o de provocar em seu leitor um certo estado de excitação da grande rede heterogênea de sua memória, ou então reorientar a sua atenção para uma certa zona de seu mundo interior, ou ainda disparar a projeção de um espetáculo multimídia na tela de sua imaginação." É isso que está acontecendo com esse grupo? na verdade surgem várias provocações, onde cada leitor, autor se identifica, contribui, concorda, discorda e assim vamos produzindo. Estamos sendo lidos como diz a Janete, e não só lidos, estamos sendo autores em conjunto. Fiquei aqui pensando em nossas produções e até chamaria (ao menos as minhas contribuições) de textos "metamorfose", pois a cada nova leitura, nova contribuição vai se transformando, seja de acordo com as necessidades, conhecimentos, leituras, reflexões, interesses, experiência... que no todo 
acontece as transformações, e o que é maravilhoso, transformações significativas... fico encantada com todas essas contribuições e participações... parabéns ao grupo

$G L-$... se eu entendo o significado é sinal que entendo a sua representação, é sinal que faço parte de um mesmo tempo, de uma mesma sociedade, de uma cultura daquele autor que estou comunicando...

O intervenção de GL expressa uma realidade encontrada no ambiente for-chat o qual, dentre alguns diálogos, discussões e interações apresentadas, encontra-se os significados e suas representações no momento em que cada um se identifica no discurso do outro, quando encontra suas respostas ao ler os diálogos. Quando ocorre o sentido, quando encontra as certezas para as hipóteses, surge a transformação, a "metamorfose" na aprendizagem, nos discursos, nas autorias, nas interações, apresentando os resultados expressos nos textos coletivos.

Os diálogos e as reflexões oportunizaram mudanças significativas nos discursos, sendo que nas relações virtuais, a convivência forchateana se destacava a cada encontro, pois as afinidades foram naturalmente se constituindo. Isso só ocorreu porque tivemos a liberdade de iniciar a leitura e as discussões de qualquer ponto das interações do texto, o que possibilitou o enriquecimento dos diálogos, reflexões e discussões.

Bakhtin, Axt, Fiorin e Barros, desencadearam outros autores na busca de sentidos e significados para as teorias estudadas, pois sem dúvida formam autores que nos fizeram pensar, re-pensar, refletir sobre o sentido de muitas práticas vividas e, mudar as práticas e os discursos em andamento e os futuros.

\section{Comunidade Virtual - Considerações finais}

Em dezenove encontros virtuais, formam 634 páginas editadas, cada uma com dez mensagens exibidas, totalizando 6.434 contribuições. Esses números nos fazem refletir sobre a aprendizagem em ambientes virtuais, pois em qual disciplina presencial ficaríam registradas todas as interações?

Foi através das interações virtuais e presenciais com a utilização do for-chat que se pode chegar a este estudo, que oportunizou aos diversos participantes construírem o conhecimento de forma interativa e coletiva formando uma comunidade virtual de aprendizagem. Paloff(2002), fundamenta a comunidade virtual dizendo: "Os participantes dependem um dos outros para alcançar os resultados exigidos pelo curso. (...) A criação de uma comunidade de aprendizagem incentiva e apóia a aquisição de conhecimento."

Salienta-se a importância de um ambiente em que se pode interagir livremente, considerando também a atuação da professora que esteve presente, instigando, orientando, mediando, incentivando, motivando e acompanhando o grupo durante as interações.

Para finalizar este artigo, ressalta-se que o Seminário envolveu todos os participantes afetivamente, propiciando uma aprendizagem significativa onde teve-se momentos para re-pensar sobre os sentidos dos discursos e das autorias, momentos de re-flexões sobre as diversas teorias apresentadas. E, foi dentro deste contexto que se formou a comunidade virtual, onde os participantes formam autores e leitores dos seus 
discursos e do discurso do outro, construindo uma comunidade virtual que agregou valores sociais e culturais num ambiente onde a voz da professora fazia-se presente na voz dos alunos. Interagir, cooperar e construir é o que buscamos em ambientes virtuais, pois esses fatores é que fazem o diferencial dos cursos presenciais.

\section{ReferênciasBibliográficas}

AXT, Margarete; MARASCHIN, Cleci. Narrativas avaliativas como categorias autopoiéticas de conhecimento..Disponível em <http://www.lelic.ufrgs.br/mead/ambiente/>

BAKHTIN, M. Estética da Criação Verbal. $3^{a}$ ed. SP, Martins Fontes, 2000.

BARROS, Diana Luz Pessoa \& FIORIN, José Luiz (orgs) Dialogismo, Polifonia, Intertextualidade. Em torno de Bakhtin. SP, EDUSP, 1999 (Ensaios de Cultura 7)

BOSSA, Nádia. A psicopedagogia no Brasil: contribuições a partir da prática. Porto Alegre, ARTMED Editora, 2000.

FERNANDEZ, Alicia. A mulher escondida na professora autora. Porto Alegre, ARTMED Editora, 1997

FERNANDEZ, Alicia. O saber em jogo. A psicopedagogia propiciando autorias de pensamento. Porto Alegre, ARTMED Editora, 2001 (cap. 5 e 6)

For-chat. Programa de interação entre alunos da disciplina Sentido e Autoria no site:<www.lelic.ufrgs.br/mead $>$.

LÉVY, Pierre. As Tecnologias da inteligência. R.J. : ed. 34. 1993.

LELIC- Laboratório de Estudos e Linguagem, Interação e Cognição. Universidade Federal do Rio Grande do Sul. Artigos publicados(site: <www.lelic.ufrgs.br/mead> Acessado no período de maio/outubro de 2002.

MONTOYA, A. Piaget e a criança favelada - Epistemologia genética, diagnóstico e soluções. Petrópolis, Vozes, 1996.

PALLOFF, Rena M.;e PRATT, Keith. Construindo Comunidades de Aprendizagem no ciberspaço. Porto Alegre : Artes Médicas, 2000. 
